\title{
Effects of laser process parameters on the hardness profile of AISI 4340 cylindrical samples: statistical and experimental analyses
}

Karim Bensalem ( $\sim$ Karim.Bensalem@uqar.ca)

Université du Québec à Rimouski: Universite du Quebec a Rimouski

Noureddine Barka

Université du Québec à Rimouski, Rimouski

Mahmoud Mouradi

Coventry University

Amimossein Sadeghian

Coventry University

Sasan Sattarpanah Karganroudi

Université du Québec à Rimouski, Rimouski

\section{Research Article}

Keywords: Laser hardening, AISI 4340 steel, microhardness profile, microstructure, statistical analysis, experimental validation

Posted Date: February 1st, 2022

DOI: https://doi.org/10.21203/rs.3.rs-1297463/v1

License: (c) (1) This work is licensed under a Creative Commons Attribution 4.0 International License. Read Full License 


\section{Abstract}

In the present paper, continuous Nd:YAG laser hardening of cylindrical AISI 4340 steel specimens was studied using experimental and statistical analyses. Three Laser parameters namely laser power, laser feed speed, and sample rotation speed were selected to evaluate their influence on the depth of the hardened zone, and the maximum surface hardness. Mathematical models were developed as a function of these three parameters and the analysis of variance (ANOVA) was used to conduct the statistical study. Microhardness measurements revealed three distinct regions in the heat-affected zone (HAZ) of all samples. The hardened zone $\left(Z_{1}\right)$ near the surface with the highest value of hardness, the hardness loss zone $\left(Z_{2}\right)$ where hardness started to decrease, and the overheated zone $\left(Z_{3}\right)$ adjacent to the core with hardness values that were less than the base metal. Based on experimental measurements, a maximum surface hardness of $60.8 \mathrm{HRC}$ was attained. Furthermore, the maximum depth of the hardened zone was observed as $500 \mu \mathrm{m}$. The microstructures of laserhardened samples were studied using optical and scanning electron (SEM) microscopies. The hardened region seemed to have hard martensitic microstructure. By comparing the predicted and measured data for maximum microhardness values it was revealed that the models represent the experimental values with correlations close to $100 \%$.

\section{Introduction}

There are several processes for improving the performance of metallic materials, specifically heat treatment techniques, which are widely used to adjust the mechanical properties to meet particular conditions of use [1-3]. However, conventional heat treatment techniques can be very costly in terms of processing time and energy utilization [3]. The advent of high-power and efficient laser systems has revolutionized several industrial fields [4]. Since this process is completely computer-aided by a robot or other CNC machines, it offers the possibility of precise localized treatments $[5,6]$.

Laser beam hardening is a surface heat treatment process that allows the rapid heating of the material's surface desired region by the energy flow conveyed via laser beam. This leads to localized austenitic transformations on the steel surface over a certain depth [7]. Thanks to the rapid cooling rates the austenite is transformed into martensite thereby increasing the surface hardness while the core is maintained at a low or medium hardness, thus optimizing the ductility and toughness of the part [8]. The amount of thermal energy required to heat the surface of the workpiece is proportional to the hardened depth and depends on several factors such as the laser process parameters, the environmental conditions around the treated workpiece, the pulsed or continuous nature of the emitted laser beam, and the chemical and physical properties of the material [9-11].

Several studies have been conducted on laser beam hardening to fully understand the interaction between the laser beam and the material, as well as the impacts of laser process parameters on the evolution of the microstructure and microhardness. Badkar et al. [12] used a statistical approach based on the utility concept and Taguchi method to find the set of optimal process parameters to maximize the width and minimize the depth of laser hardened area of commercially pure titanium. The scan speed and focal position had more effect than laser power for optimizing multiple performances. Moradi et al. [13] studied the effects of laser parameters on the depth, width, microhardness, and microstructure of the quenching area in laser hardening of AISI 420 martensitic stainless steel. By using optimum parameters, an increase of $242.86 \%$ in the microhardness of the treated surface was achieved over a width of $6.1 \mathrm{~mm}$ and a depth of $1.2 \mathrm{~mm}$. Barka and El Ouafi [14] investigated the effect of power, scan speed, and rotation speed on the hardness profile of AISI 4340 steel cylindrical samples. The sweep speed had a noticeable influence on the hardened depths, while the maximum hardness was more affected by laser power. Also, the rotation speed had an inverse effect on the surface hardness, but its effect on the hardened depth was negligible. Maamri et al. [15] carried out experimental and numerical investigations to evaluate the sensitivity of the hardened profiles to the input parameters of the laser hardening process. They declared that the beam power and scanning speed had the highest impact on the quality of the process whereas the initial hardness of the material had less impact and the effect of the surface roughness was insignificant. An investigation on the laser hardening of AISI 4130 steel performed by an Nd:YAG laser was carried out by Moradi and Karami Moghadam [16]. Increasing the laser power and decreasing the scanning speed and focal plane position, produced higher surface and average microhardness values combined with a greater depth of penetration. The effect of hardening line overlap was also analyzed, and it was found that $50 \%$ overlap gave the optimum microhardness results. Fakir et al. [17] conducted a study using the finite difference method (FDM) and proposed a model to predict the evolution of the temperature distribution profile in cylindrical AISI 4340 steel specimens as a function of laser heat treatment parameters and material properties. Using a $3 \mathrm{~kW} \mathrm{Nd:YAG} \mathrm{commercial} \mathrm{laser,} \mathrm{Ouafi} \mathrm{et} \mathrm{al.} \mathrm{[18]} \mathrm{conducted} \mathrm{an} \mathrm{experimental} \mathrm{study} \mathrm{to} \mathrm{measure} \mathrm{the} \mathrm{effect} \mathrm{of} \mathrm{laser}$ parameters on the evolution of the hardened depth of AISI 4340 spur gears. The laser power contributed more than $50 \%$, whereas the contribution of scanning and rotation speeds did not exceed $20 \%$. In another study, Fakir et al. [19] studied the evolution of static and fatigue mechanical properties of AISI 4340 steel cylindrical specimens, as a function of Nd:YAG laser process parameters. It was revealed that the fatigue endurance limit was increased by $20 \%$ in laserhardened samples. Moreover, the average deformation was limited to $0.3 \%$ compared to non-hardened specimens. The contribution of laser power, scanning speed, tooth depth, and flank inclination angle on the hardness profile of spline shafts made of AISI 4340 were analyzed by Barka et al. [20] using an analysis of variance (ANOVA). The results indicated that $70 \%$ of the hardness profile was determined by the laser power and scanning speed.

Despite these recent developments, the laser heat treatment method still has to be refined before ready-made formulations can be provided to the industry. In the present paper, the laser heat treatment of an AISI 4340 steel cylinder is investigated experimentally and statistically. The microhardness and depths of thermally affected zones are investigated. The characteristics of the laser beam are analyzed based on the equation of interaction between laser beam and material. Microscopic study is presented explaining the effects of the heat treatment on the microstructural evolution of the laser-treated area. Moreover, a statistical analysis based on ANOVA is presented to better understand the effects of each parameter individually or coupled with other parameters. Minitab software is used to generate a statistical model for each response, including the maximum hardness, the depth of the hardening zone $\left(Z_{1}\right)$, the depth of the hardness loss zone $\left(\mathrm{Z}_{2}\right)$, and the depth of the overheating zone $\left(\mathrm{Z}_{3}\right)$.

\section{Experimental Procedure}


The material used in this study was AISI 4340 medium alloy steel containing chromium, molybdenum, nickel and $0.4 \%$ carbon. Table 1 presents the chemical composition of AISI 4340 steel. Cylindrical samples with a section diameter of $\varnothing=9 \mathrm{~mm}$ were processed from quenched AISI 4340 reinforcement and subsequently tempered in the oven to normalize the core hardness at $45 \mathrm{HRC}$. Preliminary tests were conducted to determine the levels of selected parameters (laser power (LP), laser feed speed (FS), and cylindrical sample rotational speed (RS)). The L9 orthogonal Taguchi plane was used for the experimental design as presented in Table 2 .

Table 1

AISI 4340 steel chemical composition (wt. \%) [21]

\begin{tabular}{|c|c|c|c|c|c|c|c|}
\hline & $\mathrm{Fe}$ & C & Mn & $\mathrm{Si}$ & $\mathrm{Ni}$ & $\mathrm{Cr}$ & Mo \\
\hline \multirow[t]{13}{*}{ AISI 4340} & Bal. & 0.40 & 0.73 & 0.25 & 1.76 & 0.63 & 0.25 \\
\hline & & & \multicolumn{5}{|c|}{$\begin{array}{c}\text { Table } 2 \\
\text { Input parameters in the orthogonal } \\
\text { Taguchi plane. }\end{array}$} \\
\hline & & & \multirow{2}{*}{ 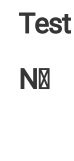 } & \multicolumn{4}{|c|}{ Factors: L9 Plan } \\
\hline & & & & $\begin{array}{l}\text { LP } \\
(W)\end{array}$ & \multicolumn{2}{|c|}{$\begin{array}{l}\text { FS } \\
(\mathrm{mm} / \mathrm{s})\end{array}$} & $\begin{array}{l}\text { RS } \\
\text { (RPM) }\end{array}$ \\
\hline & & & 1 & 1600 & 4 & \multicolumn{2}{|c|}{2000} \\
\hline & & & 2 & 1600 & 6 & \multicolumn{2}{|r|}{4000} \\
\hline & & & 3 & 1600 & 8 & \multicolumn{2}{|r|}{6000} \\
\hline & & & 4 & 2100 & 4 & \multicolumn{2}{|r|}{4000} \\
\hline & & & 5 & 2100 & 6 & \multicolumn{2}{|r|}{6000} \\
\hline & & & 6 & 2100 & 8 & \multicolumn{2}{|r|}{2000} \\
\hline & & & 7 & 2600 & 4 & \multicolumn{2}{|r|}{6000} \\
\hline & & & 8 & 2600 & 6 & \multicolumn{2}{|r|}{2000} \\
\hline & & & 9 & 2600 & 8 & \multicolumn{2}{|r|}{4000} \\
\hline
\end{tabular}

The cylindrical samples were quenched by Nd:YAG laser with a maximum power of $3 \mathrm{~kW}$ and a wavelength of $1070 \mathrm{~nm}$. The laser head was adjusted to place the focus plane on the surface of specimens. The collimator was set to its minimum level resulting in a focal spot of $1.53 \mathrm{~mm}$ in diameter. Fig. 1 presents a schematic of laser beam interaction with the rotating cylindrical specimen illustrating the different speeds used in the process; The FS speed is the feed speed of the laser head and therefore the laser beam speed. RS also noted $\omega$ is the rotation speed of the specimen. The speed (TS) is the tangential component of the rotation speed $(\omega)$ and is calculated by equation Eq. 1 and used in equation Eq. 2 to calculate the scanning speed (SS), which is the speed with which the point of impact of the laser beam on the surface of the cylindrical specimen moves. The samples were mounted on a rotating device with adjustable speed and the laser head was mounted on the FANUC m-710ic robot which had a 6-axis articulated arm allowing movements in controlled and preprogrammed directions. Fig. 2 shows the laser unit (Nd:YAG) installed on the FANUC 6-axis robot along with the important components and the sample installation device. After the laser hardening process, metallographic samples were cut, mounted with resin, polished, and finally etched with $3 \%$ Nital solution to reveal the microstructure. Moreover, microhardness tests were performed using the CLEMEX intelligent microscopy machine. The indentations were made in the radial direction of the cylindrical sections from the surface to the core of the part. the tests were conducted with a set of 50 measurements separated by a distance of $50 \mu \mathrm{m}$ and a load of $150 \mathrm{~g}$ on the indenter with a holding time of $10 \mathrm{~s}$.

$$
T S=\frac{2 \times \pi}{60} \omega \times r=\frac{\emptyset \times \pi}{60} \omega
$$

ScaningSpeed $(S S)=\sqrt{T S^{2}+V B^{2}}=\sqrt{T S^{2}+F S^{2}}$ (Eq. 2)

where TS and FS are tangential speed and feed speed respectively.

Analysis of variance (ANOVA) is a statistical approach for determining the significance of variations in sample means using methods that split the total variance of the dependent variable into two parts: variance within groups and variance across groups of the independent variable [22]. The goal of this approach is to quantify the impact of each component on the variability of the analysed responses, either separately or in conjunction with other factors. The approach suggests statistical regression models that express maximum surface hardness and depths of hardened and thermally impacted zones as a function of laser power (LP), laser feed speed (FS), and cylindrical sample rotating speed (RS). Fig. 3 is a schematic depiction of a laser-treated cylindrical specimen cross-section illustrating the multiple zones impacted by the heat treatment; three distinctive zones were identified, respectively characterised by three depths $\left(Z_{1}, Z_{2}\right.$ and $\left.Z_{3}\right) . Z_{1}$ is the depth of the hardened zone near to the surface with the maximum hardness value, $Z_{2}$ is the depth of the hardness loss zone, where the hardness decreases drastically and $Z_{3}$ is the depth of the overheated zone, acting as an intermediate zone between the hardness loss zone and the core with hardness values lower than the base metal.

\section{Results And Discussion}




\subsection{Laser beam characteristics}

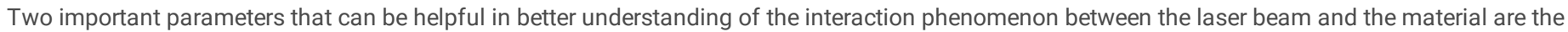

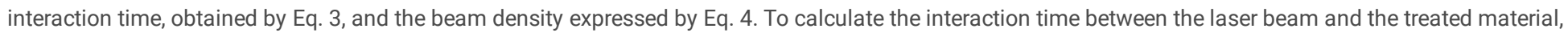
the scanning speed (SS) should be calculated first, that is, the speed at which the laser beam scans the sample surface. In this case, the speed is a

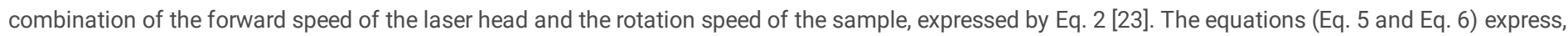

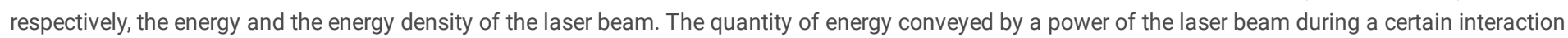

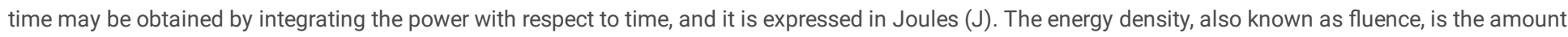
of energy per unit area of interaction and is measured in Joules per unit area $\left(\mathrm{J} / \mathrm{cm}^{2}\right)$.

Interactiontime $=\mathrm{IT}=\frac{\text { BeamDiameteratFocalposition }}{\text { ScanningSpeed }(\mathrm{SS})}=\frac{B D F}{S S}$ (Eq. 3)

Beamdensity $=\mathrm{BD}=\frac{\text { LaserPower }}{\text { AreaoftheFocalspot }}=\frac{4 \times L P}{\Pi \times B D F^{2}}$ (Eq. 4)

Energy $=L P \times$ Interactiontime $=\frac{L P \times B D F}{\mathrm{SS}}($ Eq. 5)

Energydensity $=\frac{\text { Energy }}{\text { Laserspotarea }}=\frac{4 \times L P \times B D F}{\Pi \times B D F^{2} \times \mathrm{SS}}=\frac{4 \times L P}{\Pi \times B D F \times \mathrm{SS}}=B D \times I T$ (Eq. 6)

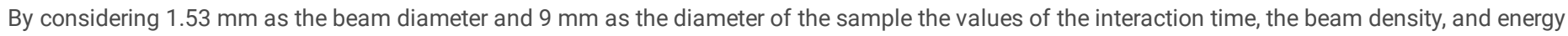
density were obtained for each test condition which are presented in Table 3.

Table 3

Calculated values for scanning speed, beam density and interaction time.

\begin{tabular}{|llllll|}
\hline Test & Tangential Speed & Scanning Speed & Beam Density & Interaction time & Energy Density \\
\hline No & $(\mathbf{m m} / \mathbf{s})$ & $(\mathrm{mm} / \mathrm{s})$ & $\left(\mathrm{W} / \mathrm{mm}^{2}\right)$ & $\left(\mathbf{s} \times \mathbf{1 0}^{-3}\right)$ & $\left(\mathrm{J} / \mathrm{mm}^{2}\right)$ \\
\hline 1 & 942,478 & 2000,00 & 870,256 & 0,765 & 0,666 \\
\hline 2 & 1884,956 & 4000,00 & 870,256 & 0,382 & 0,333 \\
\hline 3 & 2827,433 & 6000,01 & 870,256 & 0,255 & 0,222 \\
\hline 4 & 1884,956 & 4000,00 & 1142,212 & 0,382 & 0,437 \\
\hline 5 & 2827,433 & 6000,00 & 1142,212 & 0,255 & 0,291 \\
\hline 6 & 942,478 & 2000,02 & 1142,212 & 0,765 & 0,874 \\
\hline 7 & 2827,433 & 6000,00 & 1414,167 & 0,255 & 0,361 \\
\hline 8 & 942,478 & 2000,01 & 1414,167 & 0,765 & 1,082 \\
\hline 9 & 1884,956 & 4000,01 & 1414,167 & 0,382 & 0,541 \\
\hline
\end{tabular}

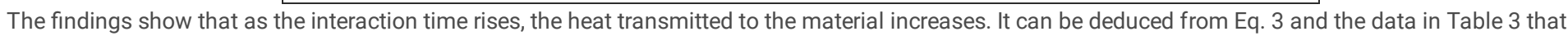

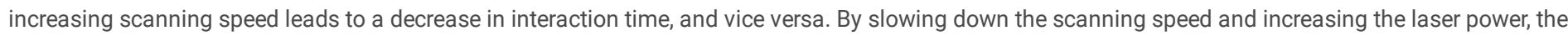

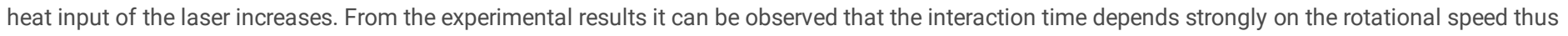
increasing the rotational speed leads to longer interaction times.

\subsection{Microhardness measurement}

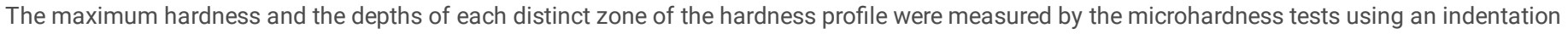

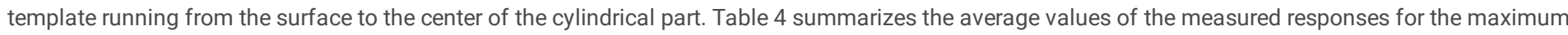
hardness, and the depth of each zone. 
Table 4

\begin{tabular}{|c|c|c|c|c|}
\hline \multirow{2}{*}{$\begin{array}{l}\text { Test } \\
\text { No }\end{array}$} & \multicolumn{4}{|l|}{ Measured responses } \\
\hline & Hardness $_{\max }(\mathrm{HRC})$ & $\mathrm{Z}_{1}(\mu \mathrm{m})$ & $\mathrm{Z}_{2}(\mu \mathrm{m})$ & $\mathrm{Z}_{3}(\mu \mathrm{m})$ \\
\hline 1 & 50,1 & 200 & 100 & 700 \\
\hline 2 & 56,8 & 100 & 100 & 650 \\
\hline 3 & 56,6 & 50 & 50 & 200 \\
\hline 4 & 54,9 & 50 & 450 & 1250 \\
\hline 5 & 57,6 & 200 & 150 & 650 \\
\hline 6 & 60,8 & 150 & 350 & 1350 \\
\hline 7 & 55,8 & 500 & 700 & 1200 \\
\hline 8 & 56,4 & 150 & 100 & 550 \\
\hline 9 & 57,9 & 500 & 200 & 1000 \\
\hline
\end{tabular}

The graphs in Fig. 4 show the experimental microhardness measurements expressed in Rockwell units as a function of depth, measured from the surface to the centre of the cylindrical specimen. These curves represent the microhardness values obtained from the cross-section of laser surface quenched samples and illustrate the variation of microhardness with quenching depth. As can be seen from Fig. 4 , the maximum hardness reached between ( 54 - 60.8 HRC) while the minimum hardness was relatively the same for all samples $(32.6-35 \mathrm{HRC})$. The laser heat treatment resulted in an average increase of $35.11 \%$ in the maximum hardness achieved on the surface. It can be seen that for a given power, the length of the hardened area was inversely proportional to the scanning speed and the rotational speed. However, it increased by increasing the laser power. The maximum hardness seemed to increase with the increase of the scanning speed. Maximum values of hardness were recorded for tests $(5,6$, and 9$)$ with values of $(57.6,60.8$, and $57.9 \mathrm{HRC})$ respectively, and the maximum values recorded for the depth of the hardened zone reached $500 \mu \mathrm{m}$ for tests ( 7 and 9$)$. The reason of this phenomena is related to the microstructural changes which is discussed in the following section.

From the results in Table 3 and Table 4, we find that the hardness and hardening depth increase with the increase of interaction time. By increasing the heat input of the laser beam, the dimensions and hardness of the laser-hardened region increase. Since the hardening tests are done on cylindrical samples, overlapping phenomenon is present which often causes a reduction in microhardness even though it increases the thermally affected depth. For a given interaction time, it can be seen that the maximum hardness increases with the increase of the feed rate which controls the percentage of overlapping of the laser lines. Also, the depths $Z_{1}$ and $Z_{2}$ increase with the increase in laser beam density. It can also be seen that for a given interaction time, the depth $Z_{3}$ increases with increasing the laser beam density and for a fixed laser beam density the depth $Z_{3}$ increases with increasing the interaction time.

\subsection{Microstructure}

Due to its excellent quenching property, martensite can be obtained in AISI 4340 steel even at relatively low cooling rates (by cooling in the air) [24]. During laser austenitizing, the hardness depends on the carbon content that is dissolved in the austenite interstitially and the quantity of alloying elements dissolved substitutively. Fig. 5 shows the overall image of the heat-affected zone (HAZ) and non-heat affected zone (core) of the laser-hardened AISI 4340 sample. The core of the piece which has kept its hardness unchanged, it has received an insignificant amount of thermal energy which has dissipated without causing any alterations. Fig. 6 shows the microstructure of AISI 4340 steel comprising of quenched martensite. It is believed that the hardening process is closely related to the phenomenon of thermally activated carbon diffusion according to reactions governed by the Arrhenius law. When the light beam strikes the surface, a large amount of energy is transmitted into the specimen. This energy raises the temperature of the impact zone above the austenitization temperature (Ac3) which creates the molten zone which is formed with hardness slightly lower than the hardened zones. This decrease can be explained by the escape of carbon in gaseous form by reacting with the oxygen in the ambient air. The hardened zone $\left(\mathrm{Z}_{1}\right)$ comes around the molten zone and receives a temperature higher than the austenitizing temperature (Ac3) but lower than the melting temperature, this causes the formation of austenitized phase which transforms into martensite almost instantaneously and independently of the cooling rate (Fig. 7). The diffusion of carbon can be activated by the high amount of absorbed thermal energy, coming from the surrounding regions the carbon can participate in the formation of martensite in this region [25]. A region characterized by a rather rapid drop in microhardness to reach minimum hardness between (32 and $35 \mathrm{HRC}$ ) is observed $\left(\mathrm{Z}_{2}\right)$. It is believed that this region corresponds to structure softened in carbon because of its diffusion leading to the loss of its hardness [9]. The drop in hardness may also be due to the recrystallization and relaxation phenomena caused by the heat conducted in this area. The neighbouring area is called the overheating area $\left(Z_{3}\right)$, it is heated but without reaching the (Ac1) temperature. This region is formed as a result of the phase transformation caused by the diffusion of carbon in the hardness drop region and by the overrecovery of the unstable martensitic phase in this region, giving it a stable martensitic structure tempered by the effect of thermal flux. It is a transitional region ensuring continuity between the core of the part not thermally affected and the carbon coated area. The last region is It can therefore be argued that laser heat treatment allows for incomplete diffusion of carbon and the hardness increases with increasing carbon content from the hardness loss zone towards the surface of the treated piece. Fig. 6 shows the microstructure taken by optical microscope and scanning electron microscope (SEM) the base metal region not affected by the laser treatment showing as-quenched martensite.

\subsection{Variance analysis and model summary}

In order to fully understand how the factors studied in this paper and their interactions affect the output parameters, statistical analysis is a very useful tool. This section discusses the analysis of variance (ANOVA) to understand the contribution of each factor. The Taguchi statistical analysis of the experimental

Page 5/18 
results has been conducted to complement the graphical analysis and evaluate the contribution of the studied factors, individually and in combination, to the depths induced by the laser hardening and to the maximum hardness reached on the surface. It is also desired to determine the optimal process parameters and to propose models for estimating the depths of the hardened zones and the maximum hardness. The optimal condition has been determined by observing the main effects of each factor, which is a good indicator of the overall impact of the factors [26]. The analysis of variance was performed on MINITAB to determine the regression coefficients and to quantify the contributions of the main effects and the interaction effects between the tested parameters [27]. Tables 5, 6, 7, and 8 summarize the relevant statistical indicators from the variance study for the maximum hardness achieved and the hardening depths $Z_{1} Z_{2}$ and $Z_{3}$. In the present ANOVA study, the stepwise method was used excluding the non-significant terms after each iteration without requiring a hierarchical model. A $95 \%$ confidence interval was considered in the statistical calculations. It can be seen that the three parameters considered in the study have an effect either individually or in combination with another factor, the effects of interactions involving three or more factors were omitted from the analysis.

\subsubsection{Effect of parameters on the maximum hardness}

The main effects graphs are used to interpret the impact of each parameter level on a given average response. A straight line connecting each two levels reflects the influence of each factor level increase on the measured responses. The steeper the slope between the two levels, the more the level of the factor in question affects the response and vice versa. Fig. 8 show the curves of variation of the maximum hardness according to the main effects related to the experimental parameters LP, FS, and RS. The significance of a factor is determined by the change in response to the change in the level of the factor, the greater the change in response the faster the change from a low to a high level of the factor and the steeper the slope in the main effects plot [28, 29]. It can be seen from Fig. 8 that the lines connecting the three levels of each factor are not horizontal, so it can be concluded that the three factors studied have an impact on the maximum hardness but with different degrees. The transition from level 1 to level 2 for LP and FS seems to have a significant effect on the maximum hardness, the slope of the line is very steep in both cases. For RS, the transition from level 1 to level 2 is done with a rather less steep slope, which induces a small change in the maximum hardness. The change from level 2 to level 3 for LP seems to have an opposite effect than the first change from level 1 to level 2. The increase of LP in this phase contributes to the decrease of the maximum hardness, which can be explained by the recurring after melting and material evaporation lead to reduced hardness. In the second pass, FS rises from level 2 to level 3 , and the slope is slightly less than that in the first pass. However, within the scope of the study, increasing the feed speed still has a great impact and helps to improve the maximum hardness. For the rotation speed, the slope of the second pass is very small, and the influence on the maximum hardness is relatively small. Table 5 summarizes the variance analysis for the maximum hardness.

According to Table 5, the feed speed (FS) is the most important factor, accounting for $53.5 \%$ of the observed hardness. Then, a contribution of $21.04 \%$ by the interaction of the sample rotational speed (RS) with the feed speed (FS), while the individual contribution of the rotational speed (RS) is irrelevant. The last important factor is laser power parameter (LP), which contributes with $11.08 \%$. The two remaining factors in the model, which account for $12.11 \%$, represent the interactions of laser power (LP) with scanning speed (FS) and laser power (LP) with sample rotating speed (RS).

Table 5

Maximum hardness variance analysis.

\begin{tabular}{|c|c|c|c|c|c|c|c|}
\hline \multicolumn{2}{|l|}{ Source } & \multirow{2}{*}{$\begin{array}{l}\text { Degree } \\
\text { of Freedom } \\
1\end{array}$} & \multirow{2}{*}{$\begin{array}{l}\text { Sum of } \\
\text { Squares } \\
7,260\end{array}$} & \multirow{2}{*}{$\begin{array}{l}\text { Contribution } \\
(\%) \\
11,08\end{array}$} & \multirow{2}{*}{$\begin{array}{l}\text { Mean } \\
\text { Squares } \\
7,260\end{array}$} & \multirow{2}{*}{$\begin{array}{l}F_{0} \\
55,17\end{array}$} & \multirow{2}{*}{$\begin{array}{l}\text { P-value } \\
0,018\end{array}$} \\
\hline Main effects & LP & & & & & & \\
\hline & FS & 1 & 35,042 & 53,50 & 35,042 & 266,30 & 0,004 \\
\hline & RS & 1 & 1,215 & 1,86 & 1,215 & 9,23 & 0,093 \\
\hline \multirow{5}{*}{$\begin{array}{l}\text { Two-factors } \\
\text { Interactions }\end{array}$} & $\mathrm{LP} \bullet \mathrm{FS}$ & 1 & 3,721 & 5,68 & 3,721 & 28,28 & 0,034 \\
\hline & $\mathrm{FS} \cdot \mathrm{RS}$ & 1 & 13,783 & 21,04 & 13,783 & 104,74 & 0,009 \\
\hline & $\mathrm{LP} \bullet \mathrm{RS}$ & 1 & 4,212 & 6,43 & 4,212 & 32,01 & 0,030 \\
\hline & Error & 2 & 0,263 & 0,40 & 0,132 & & \\
\hline & Total & 8 & 65,496 & 100 & & & \\
\hline \multicolumn{3}{|c|}{ R-Squared = \% 99.6} & \multicolumn{4}{|c|}{ R-Squared (Adj) = \% 98.39} & \\
\hline
\end{tabular}

Our observations can be confirmed by the P-value in Table 5. Factors with a P value less than $5 \%$ are important variables and make significant contributions to the statistical model. Similarly, by comparing the $F_{0}$ value of each variable with the critical $F$ value taken from the percentage point tables of the $F$ distribution [29], the critical $F$ value can be obtained using the Eq. 7. The results show that all model parameters influence the maximum hardness, except the rotational speed (RS) which has no significant effect on the maximum hardness. Fig. 9 is a graphical representation of Eq. 8, it expresses the evolution on a surface curve of the maximum hardness as a function of the feed rate and the laser power in (a), as a function of the rotation speed and the laser power in (b) and as a function of the feed rate and the rotation speed (c). These curves are very useful from the point of view of optimization and choice of optimal parameters in order to obtain the desired hardness.

It can be seen that the maximum hardness is obtained by increasing the heat input, the latter increases with the increase of the laser power and is inversely proportional to the scan speed. Remember that the scan speed is composed of the rotation speed and the feed speed. On the curve in figure 9 (a), the greater 
the feed speed, the more important the hardness is, because the function of the feed speed is to move the laser beam from a cross section of the specimen to another.

On the curve of the graph 9 (b), the value of the hardness increases with the increase of the laser power and decreases with the increase of the rotation speed, which is due to the phenomenon of overlapping which increases with the increase of the rotation speed.

On the curve of the graph 9 (c), the maximum value of hardness can be read when the feed speed is maximum and the workpiece rotational speed is minimum. On the other hand, when the feed speed is small and the rotational speed is high, the percentage of overlap of the laser lines will increase which may have the opposite effect on hardening by tempering the previously treated area.

$F_{C}=F_{\alpha, D D L_{1}, D D L_{2}}=F_{0.05,1,2}=18.51($ Eq. 7$)$

$H R C_{\text {max }}=27,94+2,312 \times F S+10,23 \cdot 10^{-3} \times R S+(1071 \times F S-460) 10^{-6} \times L P-(957 \times F S+2 \times L P) \cdot 10^{-6} \times V R(E q .8)$

\subsubsection{Effect of parameters on the hardened zones depth}

Figure 10 shows the effects of the factors (LP), (FS), and (RS) on the depth $Z_{1}$ shown in blue color, $Z_{2}$ shown in purple color, and $Z_{3}$ shown in red color. At first sight, it has been found that the lines connecting the three levels of each factor are not horizontal, which means that the three factors studied have an impact on the depths studied but with different degrees. The transition from level (1) to level (2) for (LP) occurred with a less steep slope for the $Z_{1}$ depth, so it can be said that the effect of power on $Z_{1}$ in this interval fringe is not very significant. In the case of $Z_{2}$, the increase of (LP) in this area caused a considerable increase of $74 \%$ on $Z_{2}$. While this increase has been done with a pronounced slope for $Z_{3}$, causing a considerable increase of $52.31 \%$. The transition from level (2) to level (3) for (LP) is 15 times steeper than the first transition for $Z_{1}$, so the effect of the increase in (LP) is 15 times steeper when moving to the third level. For the depth $Z_{2}$, an increase of $4.99 \%$ on $Z_{2}$ has been generated by the increase of (LP) in this scale. For the depth $Z_{3}$, the passage was made with a medium and negative slope, a decrease of $18,18 \%$ on $Z_{3}$ has been generate by the increase of (LP) in this range.

The transition from level (1) to level 2) of factor (FS) occured with a steep and negative slope, increasing (FS) in this interval has both a large and inverse effect on the depth $Z_{1}$. Concerning the depth $Z_{2}$, the passage was made with a more important and negative slope, a fall of $72 \%$ of the depth $Z_{2}$ has been engendered by the increase of (FS) in this first passage. The passage was made with an even more important and negative slope, the increase of (FS) in this first passage caused a fall of $70,27 \%$ of the depth $Z_{3}$. The increase of (FS) at level (3) was done with a positive and important slope, the depth $Z_{1}$ increased with the increase of (FS) in this case. For the depth $Z_{2}$, the passage was made with an important and positive slope, the increase of (FS) in this zone leads to a gain of $41,66 \%$ of the depth $Z_{2}$. The passage was made with a moderately large and positive slope, leading to a gain of $27.45 \%$ on the $Z_{3}$ depth.

For (RS), the transition from level (1) to level (2) was rather less steep, the effect of (RS) on $Z_{1}$ in this interval is minimal. This passage was made with a moderate slope generating an increase of $26,6 \%$ on the depth $Z_{2}$. Concerning the depth $Z_{3}$, this passage was made with a moderate slope generating an increase of $10,34 \%$. The transition from level (2) to level (3) for (RS) seems to have less effect than the first transition, which was done with a greater three-half slope for the $Z_{1}$ depth. Similarly, for depth $Z_{2}$, the passage was made with a moderate slope generating an increase of $16.66 \%$. Contrary to depths $Z_{1}$ and $Z_{2}$, depth $Z_{3}$ seems to be affected by this transition with a significant and negative slope, causing a drop of $41.46 \%$.

\subsubsection{Effect of parameters on $Z_{1}$ depth}

Table 6 summarizes the descriptive statistical parameters of the variance analysis performed on the hardening depth $Z_{1}$; we can see that the laser power (LP) has the highest contribution of $44.65 \%$. Sweep speed (FS) appears to have no significant effect on $\mathrm{Z}_{1}$ depth, while rotational speed (RS) has a small contribution of $4.36 \%$. The total contribution of two-factor interactions is estimated at $50.79 \%$. The individual effect of scan speed (FS) is insignificant, but its interaction with laser power (LP) or rotation speed (RS) seems to affect the curing depth. The P-values in the Table 6 are all less than $5 \%$ except for the P-value of the scan speed factor (FS). The same observation is made for the value of $F_{0}$, all the values of $F_{0}$ are higher than the critical $F$ value except that of the scan speed (FS). 
Table 6

Analysis of variance of the hardened depth $\mathrm{Z}_{1}$.

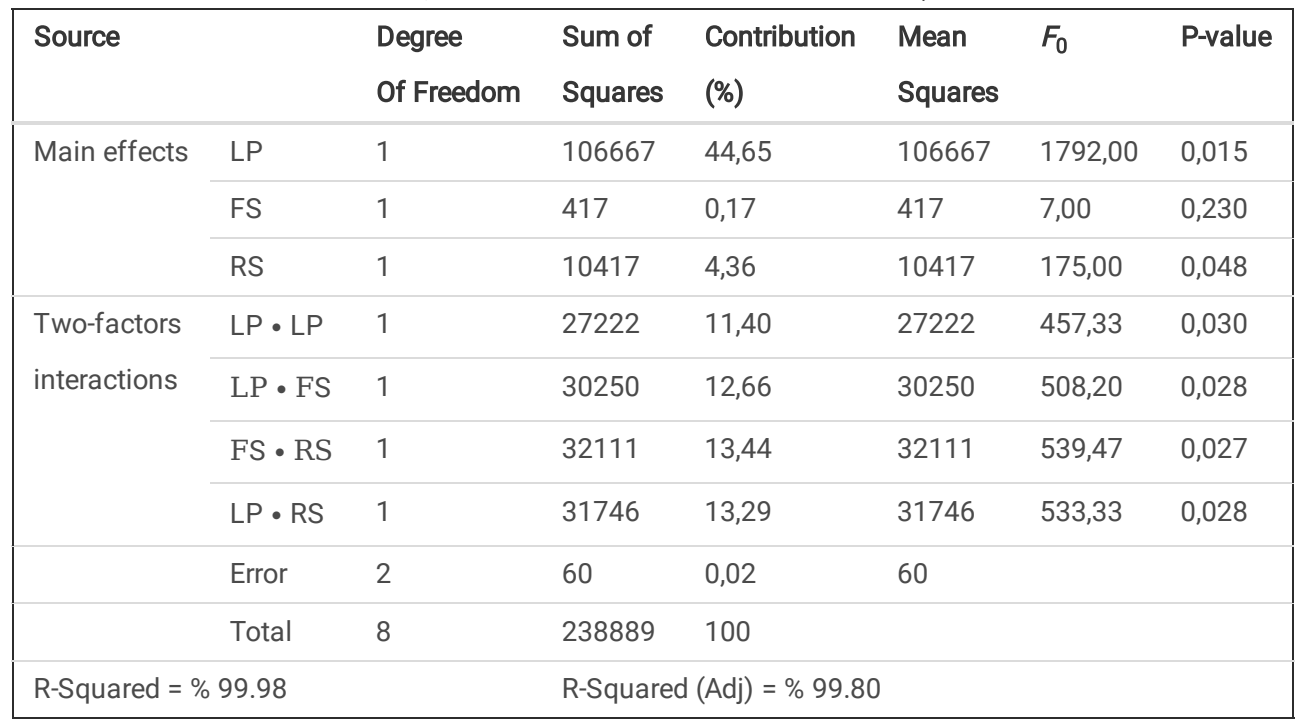

For a confidence level $\mathrm{a}=5 \%$ one can find the critical value of $\mathrm{F}_{\mathrm{c}}$ from the percentage point tables of the $\mathrm{F}$ distribution [29] according to Eq. 5 ,

$F_{0.05,1,1}=161.4$.

It can be seen that all the parameters of the model represented by Eq. 9, have an effect on the hardening depth except the feed speed (FS) which has no significant effect.

$Z_{1}(\mu \mathrm{m})=3049-2,363 \times L P-31,5 \times F S-0,4107 \times R S+0,02381 \times L P \times F S+(417 \times L P \times L P+6250 \times F S \times R S+190 L P \times R S) \cdot 10^{-6}$ (Eq. 9)

Figure 11 is a graphical representation of Eq. 9 , it expresses the evolution on a surface curve of the hardened region depth $Z_{1}$ as a function of the feed speed and the laser power in (a), as a function of the rotation speed and the laser power in (b) and as a function of the feed speed and the rotation speed (c). In order to obtain higher values of the depth $Z_{1}$, the laser power, the feed speed and the rotation speed of the workpiece, must be set to the maximum in their studied intervals.

\subsubsection{Effect of parameters on $\mathrm{Z}_{2}$ depth}

For the depth $Z_{2}$ representing the hardness loss zone, it can be seen from Table 7 that the model contains six important terms. The interaction coefficient between scanning speed (FS) and rotating speed (RS) contributes the most, accounting for $29.62 \%$, followed by laser power, accounting for $25.19 \%$. The third and fourth positions are scanning speed factor and second-order interaction of scanning speed factor (FS $\times$ FS), and their contribution rates are $18.92 \%$ and $19.03 \%$ respectively. In the depth model of $Z_{2}$, the rotational speed factor (RS) contributes $5.49 \%$, and the interaction factor between laser power and rotational speed (RS) contributes 1.69\%. The P-values in Table 7 are less than $5 \%$, which indicates that all variables are important in the statistical model and have significant contributions.

Table 7

Variance analysis of hardening depth $\mathrm{Z}_{2}$.

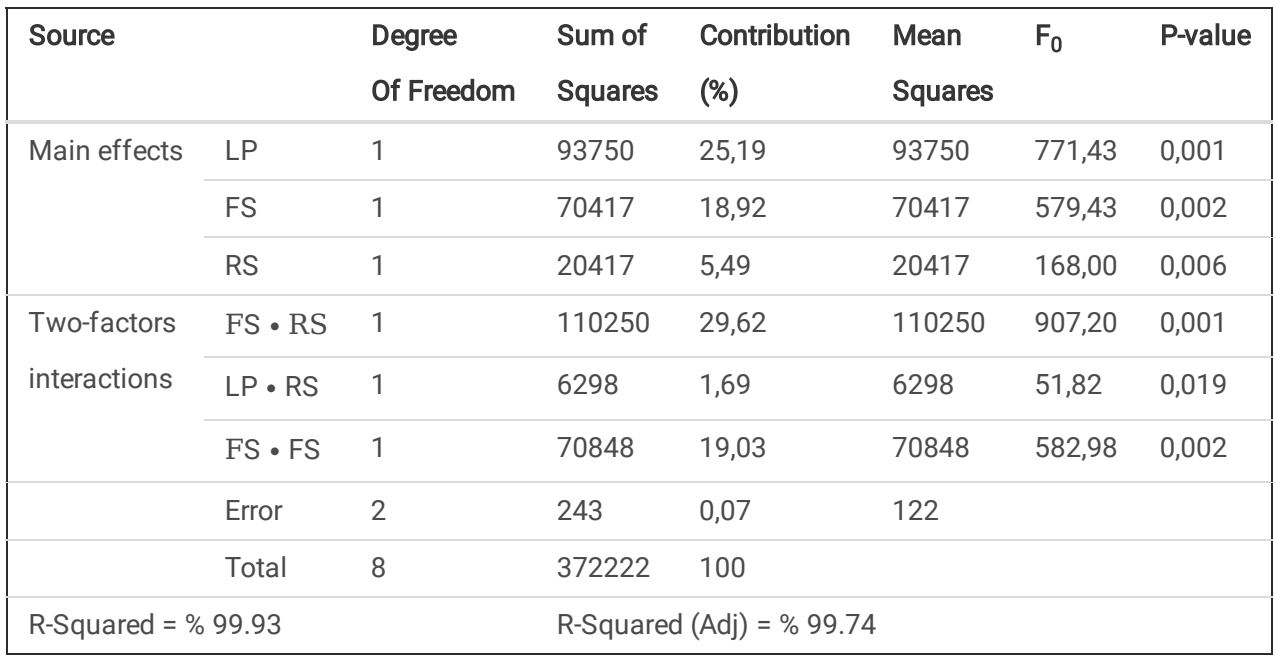

This can be confirmed by comparing the $F_{0}$ value of each variable with the critical $F_{C}$ value in the percentage table of distribution $F$ [29]. For the confidence level $a=5 \%$, the critical $F_{C}$ value can be found according to $E q .7, F_{0.05,1,2}=18.51$. 
The model obtained by the statistical analysis for the depth of hardness loss zone $Z_{2}$ is formulated by Eq. 10 and represented graphically in Fig. 12 . It can be clearly seen that the maximum on depth $Z_{2}$ can be obtained when the laser power is high enough between $2400 \mathrm{~W}$ and $2600 \mathrm{~W}$, and the feed and rotation speeds are set to their minimum and maximum respectively. We can therefore deduce that the depth $Z_{2}$ increases with the increase in the amount of the heat received by the treated workpiece.

$Z_{2}(\mu \mathrm{m})=500,3+0,2125 \times L P-483,9 \times F S+0,4735 \times R S+53,91 \cdot(F S \times F S)-48 \times 10^{-6}(L P \times R S)-0,05729 \cdot(F S \times R S)(E q .10)$

\subsubsection{Effect of parameters on depth $Z_{3}$}

For the overtempered zone depth specified by $Z_{3}$, it can be seen from Table 8 that the model includes six important parameters and seven degrees of freedom for the considered confidence interval. The laser power (LP) contributes $20.53 \%$, as the factors rotational speed (RS) and scanning speed (FS) were considered insignificant and were excluded from the model. The interaction factor between laser power and rotation speed (LP $\times$ RS) has the largest contribution of $38.19 \%$. The second-order interaction factor of the laser power ( $L P \times L P)$ contributes with $23.00 \%$, the remaining interaction factors having an effect in the model of the depth of the $Z_{3}$ superheat zone participate with small contributions included in the interval $(1.71-7.35)$, for an overall contribution totaling $18.27 \%$.

Table 8

Variance analysis of the hardened depth $\mathrm{Z}_{3}$

\begin{tabular}{|c|c|c|c|c|c|c|c|}
\hline \multicolumn{2}{|l|}{ Source } & \multirow{2}{*}{$\begin{array}{l}\text { Degree } \\
\text { Of Freedom } \\
1\end{array}$} & \multirow{2}{*}{$\begin{array}{l}\text { Sum of } \\
\text { Squares } \\
240000\end{array}$} & \multirow{2}{*}{$\begin{array}{l}\text { Contribution } \\
\text { (\%) } \\
20,53\end{array}$} & \multirow{2}{*}{$\begin{array}{l}\text { Mean } \\
\text { Squares } \\
131026\end{array}$} & \multirow{2}{*}{$\begin{array}{l}F_{0} \\
738,60\end{array}$} & \multirow{2}{*}{$\begin{array}{l}\text { P-value } \\
0,023\end{array}$} \\
\hline Main effects & LP & & & & & & \\
\hline \multirow{8}{*}{$\begin{array}{l}\text { Two-factors } \\
\text { Interactions }\end{array}$} & $L P \bullet L P$ & 1 & 268889 & 23,00 & 161364 & 909,62 & 0,021 \\
\hline & $\mathrm{FS} \cdot \mathrm{FS}$ & 1 & 39470 & 3,38 & 172814 & 974,16 & 0,020 \\
\hline & $\mathrm{RS} \cdot \mathrm{RS}$ & 1 & 68098 & 5,83 & 124148 & 699,83 & 0,024 \\
\hline & $\mathrm{LP} \bullet \mathrm{FS}$ & 1 & 85934 & 7,35 & 68388 & 385,50 & 0,032 \\
\hline & $\mathrm{LP} \cdot \mathrm{RS}$ & 1 & 446348 & 38,19 & 410900 & 2316,26 & 0,013 \\
\hline & $\mathrm{FS} \cdot \mathrm{RS}$ & 1 & 19973 & 1,71 & 19973 & 112,59 & 0,060 \\
\hline & Error & 1 & 177 & 0,02 & 177 & & \\
\hline & Total & 8 & 1168889 & 100 & & & \\
\hline \multicolumn{3}{|c|}{ R-Squared = \% 99.98} & \multicolumn{5}{|c|}{ R-Squared $($ Adj $)=\% 99.88$} \\
\hline
\end{tabular}

The P-values in Table 8 are all less than $5 \%$, which implies that all variables are significant and contribute significantly to the statistical model, except for the interaction (FS•RS) where the P-value is $6 \%$. This remark can be confirmed by comparing the $F_{0}$ values of each variable with the critical $F_{c}$ value taken from the percentage point tables of the $\mathrm{F}$ distribution [29], for a confidence level $\mathrm{a}=5 \%$ the critical value of $F_{c}\left(F_{c}=F_{0.05,1,1}=161.4\right)$ was calculated according to Eq. 7.

The model obtained by the statistical analysis for the depth of over-tempering zone $Z_{3}$ is expressed by Eq. 11 and represented graphically in Fig. 13 . it can be seen that the depth $Z_{3}$ is maximized by average values of the laser power around $(2100-2600 \mathrm{~W})$, feed speed at minimum and maximum values and average values of the rotation speed. The graph (c) of Fig. 13, tells us that there are two combinations to maximize the $Z_{3}$ value. When the laser power is set to $2100 \mathrm{~W}$, the feed speed must be at its maximum and the rotation speed must be at its minimum, and when the laser power is set to $2600 \mathrm{~W}$, the feed speed must be at its minimum and the rotation speed must be at its maximum. It can be understood that the depth $\mathrm{Z}_{3}$ is proportional to the interaction time between the laser beam and the material.

$Z_{3}(\mu \mathrm{m})=-4918+5,560 \times L P-0,001268(L P \times L P)+43,90(F S \times F S)-(73(R S \times R S)+304(L P \times R S)) 10^{-6}-0,19120(L P \times F S)-0,024^{\prime}$ (Eq. 11)

The proposed statistical models demonstrate excellent reproducibility of the experimental results, with a maximum error of $2.66 \%$ for the maximum hardness approximation model. We also report very low maximum errors on the hardness depth approximation models, with errors of $5.748 \%, 5.113 \%$, and $2.68 \%$ for depths $Z_{1}, Z_{2}$, and $Z_{3}$, respectively.

\section{Conclusions}

Laser hardening of AISI 4340 steel was analysed in this study using ANOVA. Furthermore, the effects of the laser process parameters on the maximum surface hardness and the different depths of the heat-affected zones were investigated. The proposed mathematical models show excellent reproducibility of the experimental data, with a maximum error of $2.66 \%$ for the maximum hardness approximation model. The maximum errors on the hardness depth approximation models are also very small, with errors of $5.748 \%, 5.113 \%$, and $2.68 \%$ for the $Z_{1}, Z_{2}$, and $Z_{3}$ depths, respectively. The maximum hardness prediction model is reasonably accurate with an error of $2.615 \%$. The three factors considered in this study (laser power, feed speed, and sample rotational 
speed) resulted in a maximum hardness of $60.8 \mathrm{HRC}$ and a maximum depth of $500 \mu \mathrm{m}$ for the hardened zone. From the statistical analysis, the factors that had the greatest impact on the responses were determined:

- Feed speed (FS) is the most important factor affecting the maximum hardness with a contribution of $53.5 \%$.

- For the hardened depth $Z_{1}$, laser power (LP) is the most influential factor with the highest contribution of $44.65 \%$.

- The modeling of the depth of the hardness loss zone $Z_{2}$ has six important parameters. The interaction factor of feed speed with rotational speed (FS $\times$ RS) had the highest contribution of $29.62 \%$, followed by laser power with $25.19 \%$.

- The most important and influential factor on the depth of the overheat zone denoted by $Z_{3}$ is the interaction factor between laser power and rotational speed (LP $\times$ RS) showing a contribution of $38.19 \%$, followed by the second-order interaction factor of laser power (LP $\times$ LP) contributing with $23.00 \%$.

\section{Declarations}

Funding: This research received no specific grant from any funding agency in the public, commercial, or not-for-profit sectors.

Data availability : All data, material, and codes used in this paper are available.

Ethical approval : This article does not involve human or animal participation or data; therefore, ethics approval is not applicable.

Consent to participate: This article does not involve human or animal participation or data; therefore, consent to participate is not applicable.

Consent to publish : This article does not involve human or animal participation or data; therefore, consent to publication is not applicable.

Conflicts of Interest : The authors declare no conflict of interest.

\section{References}

1. Mahdi H, Ouafi AE, Barka N (2017) Prediction of the hardness profile of an AISI 4340 steel cylinder heat-treated by laser - 3D and artificial neural networks modelling and experimental validation,. J Mech Sci Technol 31:615-623. doi: 10.1007/s12206-017-0114-4

2. Ian H, Philip S (2017) "7 - Surface engineering," pp. 237-281, doi: https://doi.org/10.1016/B978-0-08-100910-9.00007-6

3. Naidu BG (2011) Laser surface hardening: A review,. Int J of Surface Science and Engineering 5(151):131. doi: 10.1504/IJSURFSE.2011.041398

4. Jüptner WP (2001) "LIA handbook of laser materials processing-John F. Ready (Editor in Chief), Dave F. Farson (Associate Editor); Laser Institute of America/Magnolia Publishing/Springer, Berlin, ; 715 pages; price DM 466, Hardback, ISBN: 3-540-41770-2," Optics and Lasers in Engineering, vol. 6, no. 38, pp. 608-610, 2002

5. Kannatey-Asibu E Jr (2009) Principles of laser materials processing. John Wiley \& Sons

6. Moradi M, Arabi H, Kaplan AF (2019) An experimental investigation of the effects of diode laser surface hardening of AISI 410 stainless steel and comparison with furnace hardening heat treatment,. Journal of the Brazilian Society of Mechanical Sciences and Engineering 41(10):1-11

7. Ericsson T (1986) "Thermal and austenitic thermochemical surface hardening of steel," Pergamon Press, Advances in Surface Treatments. TechnologyApplications-Effects., vol. 2, pp. 3-20,

8. Kennedy E, Byrne G, Collins DN "A review of the use of high power diode lasers in surface hardening,"Journal of Materials Processing Technology, vol.155-156, pp. 1855-1860, 2004/11/30/ 2004, doi: https://doi.org/10.1016/j.jmatprotec.2004.04.276

9. Ashby M, Easterling KE (1984) The transformation hardening of steel surfaces by laser beams-I. Hypo-eutectoid steels,. Acta Metall 32(11):1935-1948

10. ghazi-jerniti A, El Ouafi A, Barka N (2016) "Single Track Laser Surface Hardening Model for AISI 4340 Steel Using the Finite Element Method,". Modeling and Numerical Simulation of Material Science 06:17-27. doi: 10.4236/mnsms.2016.62003

11. Maharjan N, Zhou W, Wu N (2020) Direct laser hardening of AISI 1020 steel under controlled gas atmosphere,. Surface and Coatings Technology $385: 125399$

12. Badkar DS, Pandey KS, Buvanashekaran G (2011) "Parameter optimization of laser transformation hardening by using Taguchi method and utility concept,". The International Journal of Advanced Manufacturing Technology 52(9):1067-1077. doi: 10.1007/s00170-010-2787-z. /02/01 2011

13. Moradi M, Fallah MM, Nasab SJ (2018) Experimental study of surface hardening of AISI 420 martensitic stainless steel using high power diode laser. Trans Indian Inst Met 71(8):2043-2050

14. Barka N, Ouafi AE (2015) Effects of Laser Hardening Process Parameters on Case Depth of 4340 Steel Cylindrical SpecimeŽ A Statistical Analysis,. Journal of Surface Engineered Materials and Advanced Technology 05:124-135

15. Maamri I, Barka N, El Ouafi A (2018) "ANN Laser Hardening Quality Modeling Using Geometrical and Punctual Characterizing Approaches," Coatings, vol. 8, doi: 10.3390/coatings8060226

16. Moradi M, KaramiMoghadam M (2019) "High power diode laser surface hardening of AISI 4130; statistical modelling and optimization," (in English), Opt Laser Technol, vol. 111, pp. 554-570, Apr doi: 10.1016/j.optlastec.2018.10.043

17. Fakir R, Barka N, Brousseau J (2018) Case study of laser hardening process applied to 4340 steel cylindrical specimens using simulation and experimental validation,. Case Studies in Thermal Engineering 11:15-25

18. Borki AE, Ouafi, Chebak (2019) "Experimental Investigation of Laser Surface Transformation Hardening of 4340 Steel Spur Gears,". Journal of Manufacturing and Materials Processing 3:72. doi: 10.3390/jmmp3030072

Page $10 / 18$ 
19. Rachid F, Noureddine B, Jean B, Gabriel C-G (2020) Analysis of the Mechanical Behavior of AISI 4340 Steel Cylindrical Specimens Heat Treated with Fiber Laser,. J Manuf Process 55:41-56. doi: https://doi.org/10.1016/j.jmapro.2020.03.039

20. Barka N, Sattarpanah Karganroudi S, Fakir R, Thibeault P, Feujofack Kemda VB (2020) "Effects of Laser Hardening Process Parameters on Hardness Profile of 4340 Steel Spline-An Experimental Approach," Coatings, vol. 10, no. 4, p. 342,

21. Algarni M, Bai Y, Choi Y (2015) "A study of Inconel 718 dependency on stress triaxiality and Lode angle in plastic deformation and ductile fracture,". Eng Fract Mech 147:140-157

22. Mason RL, Gunst RF, Hess JL (2003) Statistical design and analysis of experiments: with applications to engineering and science. John Wiley \& Sons

23. Moradi M, KaramiMoghadam M (2019) High power diode laser surface hardening of AISI 4130; statistical modelling and optimization,. Opt Laser Technol $111: 554-570$

24. Callister WD (2000) Fundamentals of materials science and engineering. Wiley London,

25. Askeland DR, Phulé PP, Wright WJ, Bhattacharya DK (2003)"The science and engineering of materials,"

26. Lawson J (2014) Design and Analysis of Experiments with R. CRC press

27. Roy RK, Rāẏa R (1990) A Primer on the Taguchi Method. Van Nostrand Reinhold

28. Temmler A et al (2020) "Influence of laser polishing on surface roughness and microstructural properties of the remelted surface boundary layer of tool steel H11,". Mater Design 192:108689

29. Montgomery DC (2012) Design and Analysis of Experiments, 8th Edition. John Wiley \& Sons, Incorporated,

\section{Figures}

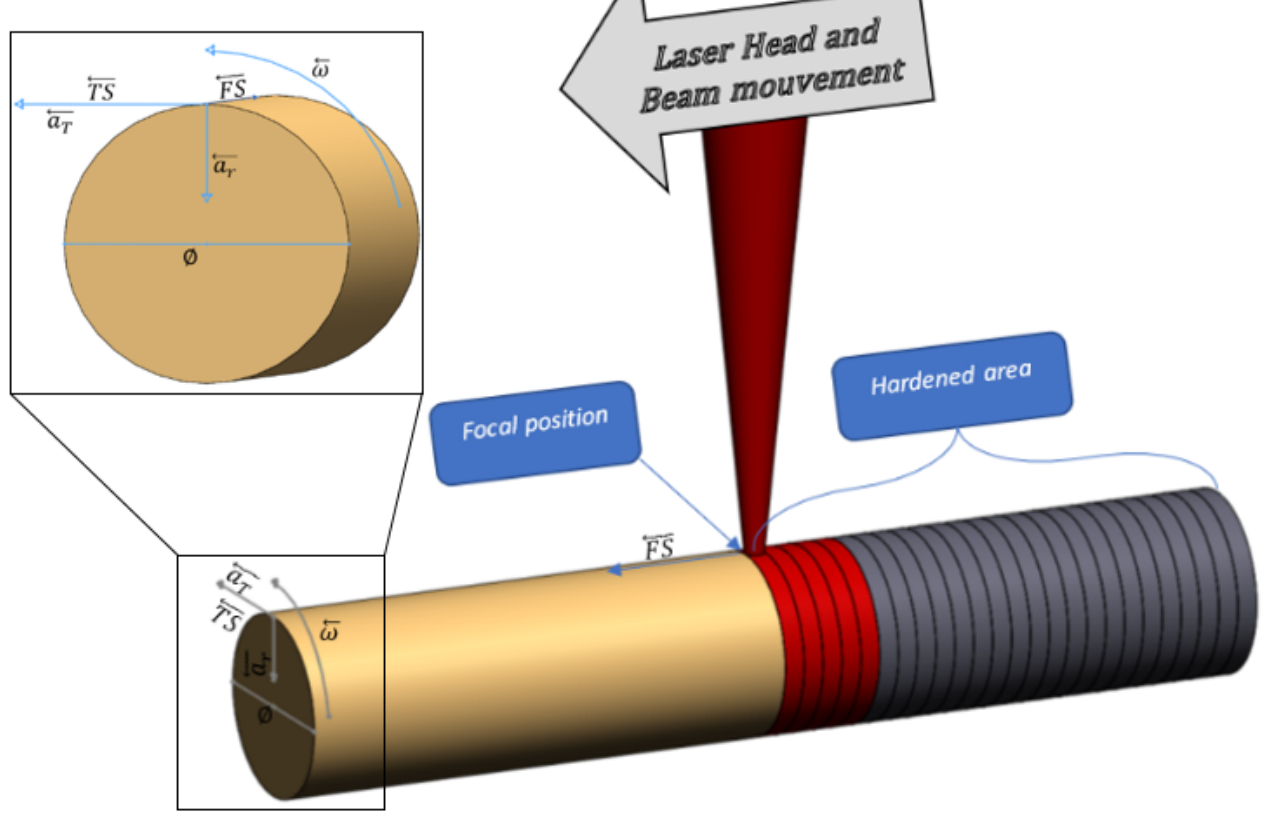

Figure 1

Schematic illustration of the laser treatment process on a rotating cylindrical sample. 


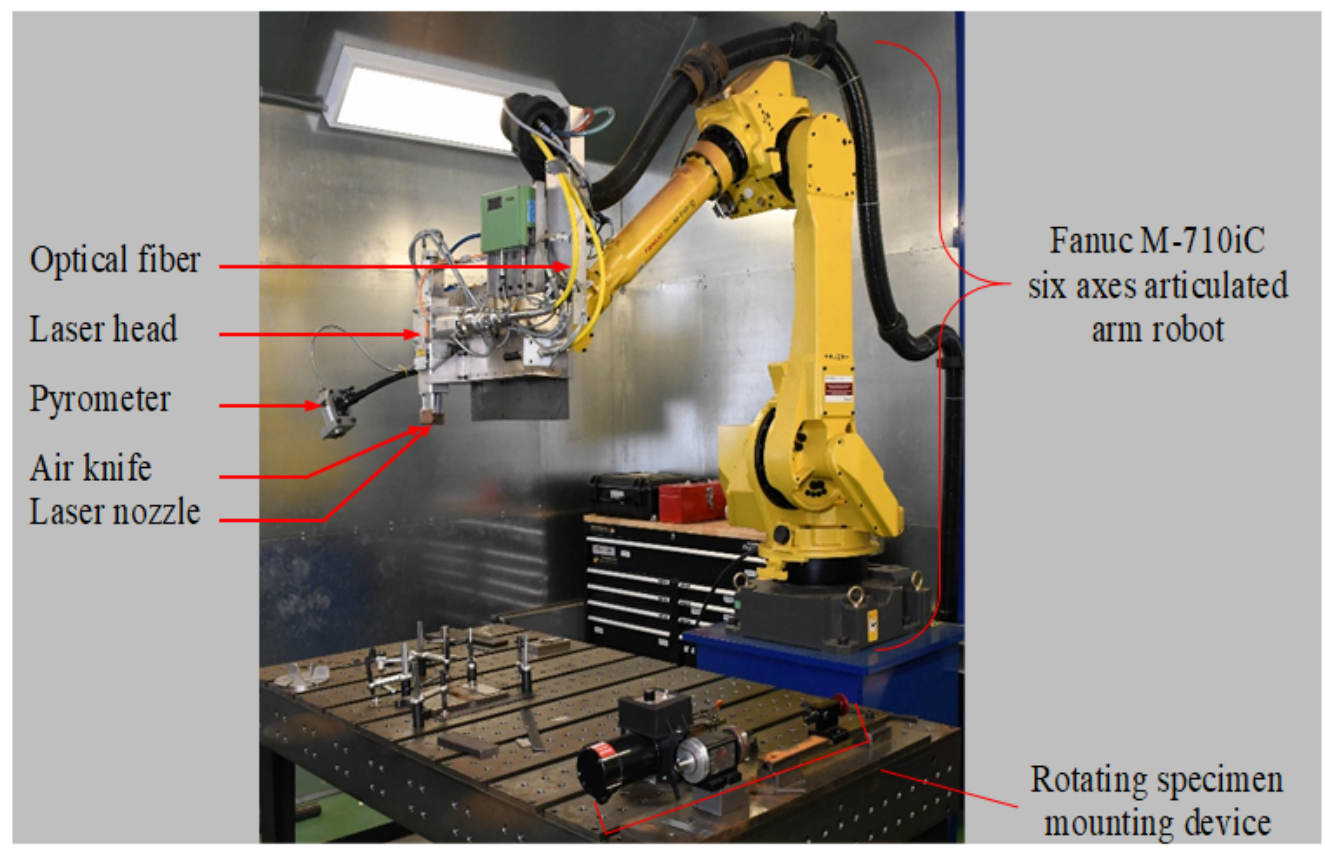

Figure 2

Laser cell (3 kW Nd:YAG) mounted on a FANUC robot with 6 axes.

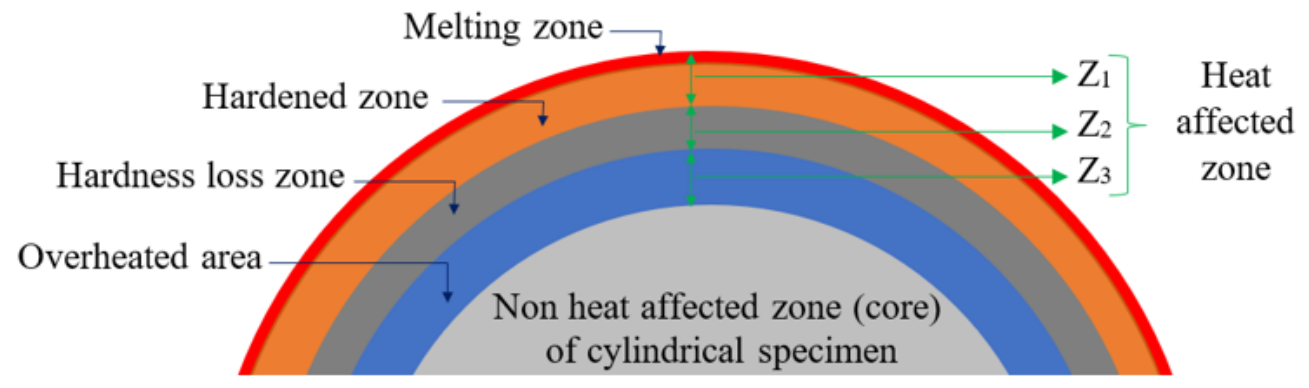

Figure 3

Cross-section representing the areas affected by laser hardening. 

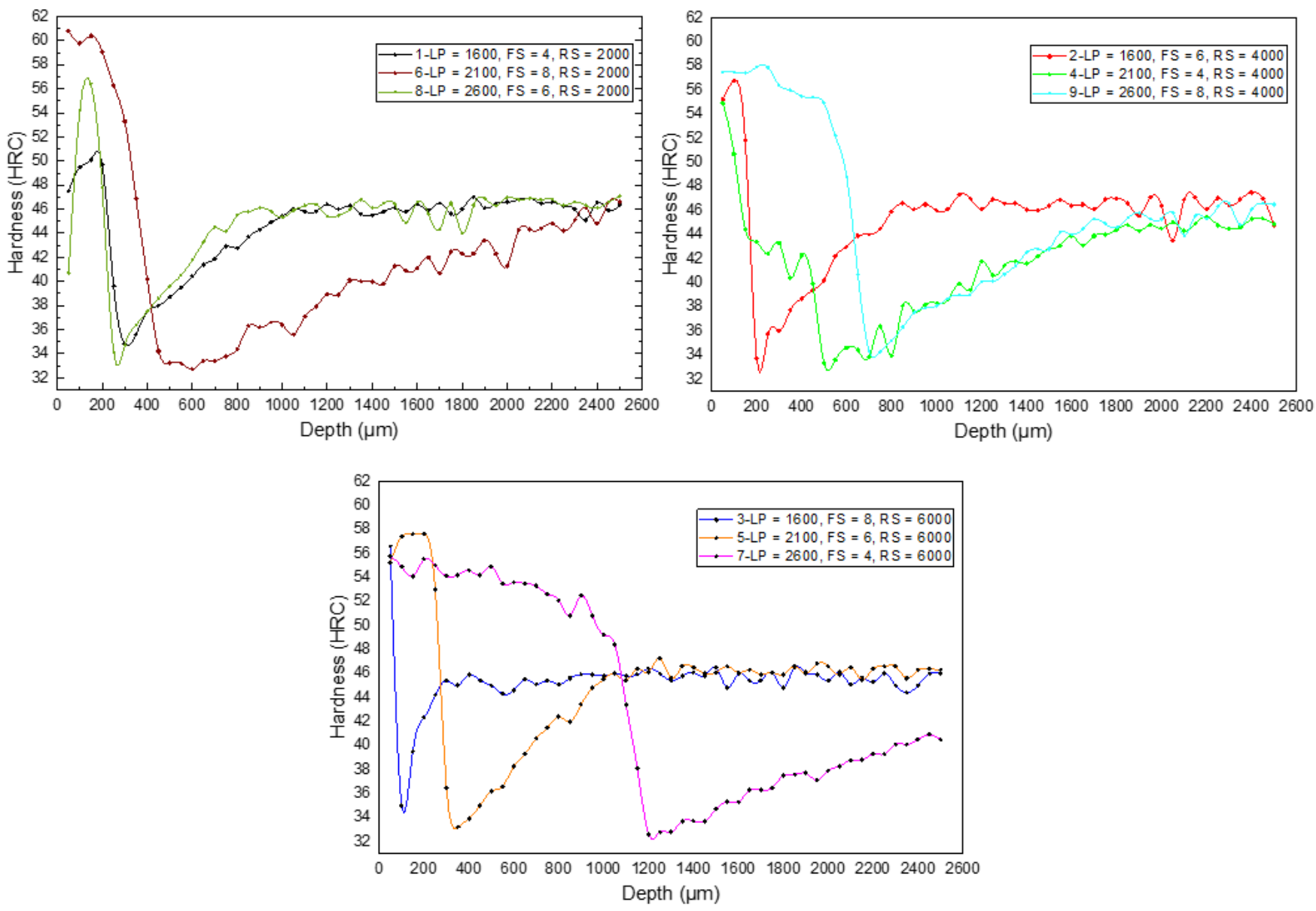

Figure 4

Curing curve as a function of curing depth for the three factors LP (W), FS (mm/s), and RS (MRP) with their three levels.

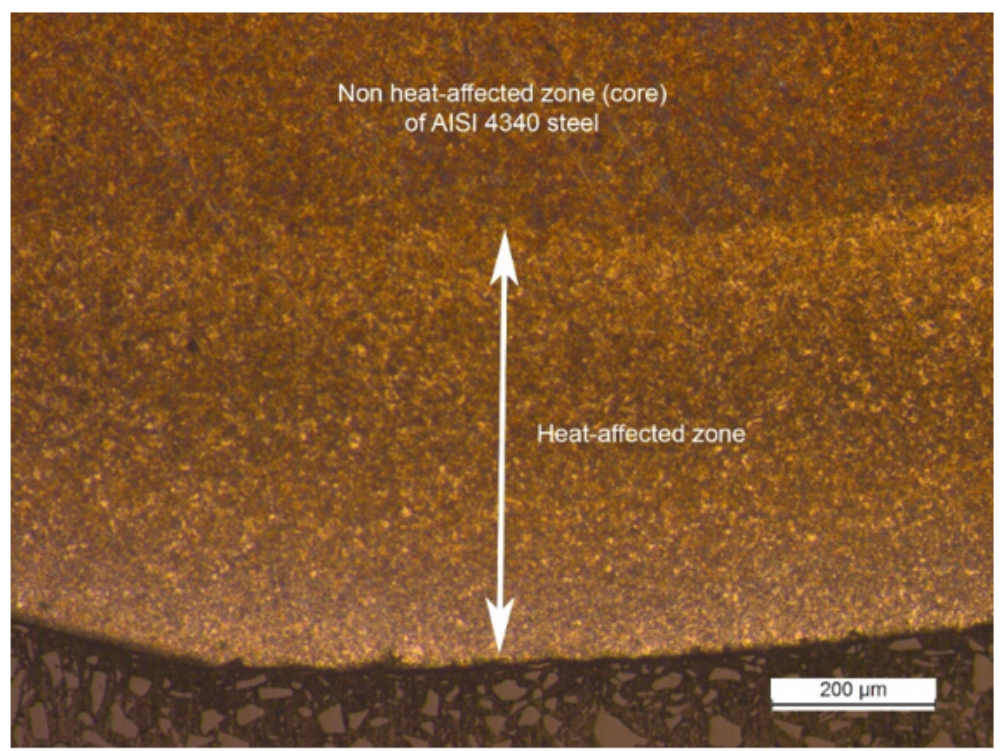

\section{Figure 5}

Optical micrograph showing heat-affected zone and core of laser-hardened AISI 4340 steel. 


\section{Figure 6}

The as-quenched martensite (core) of the AISI 4340 steel (a) optical micrograph (b) SEM
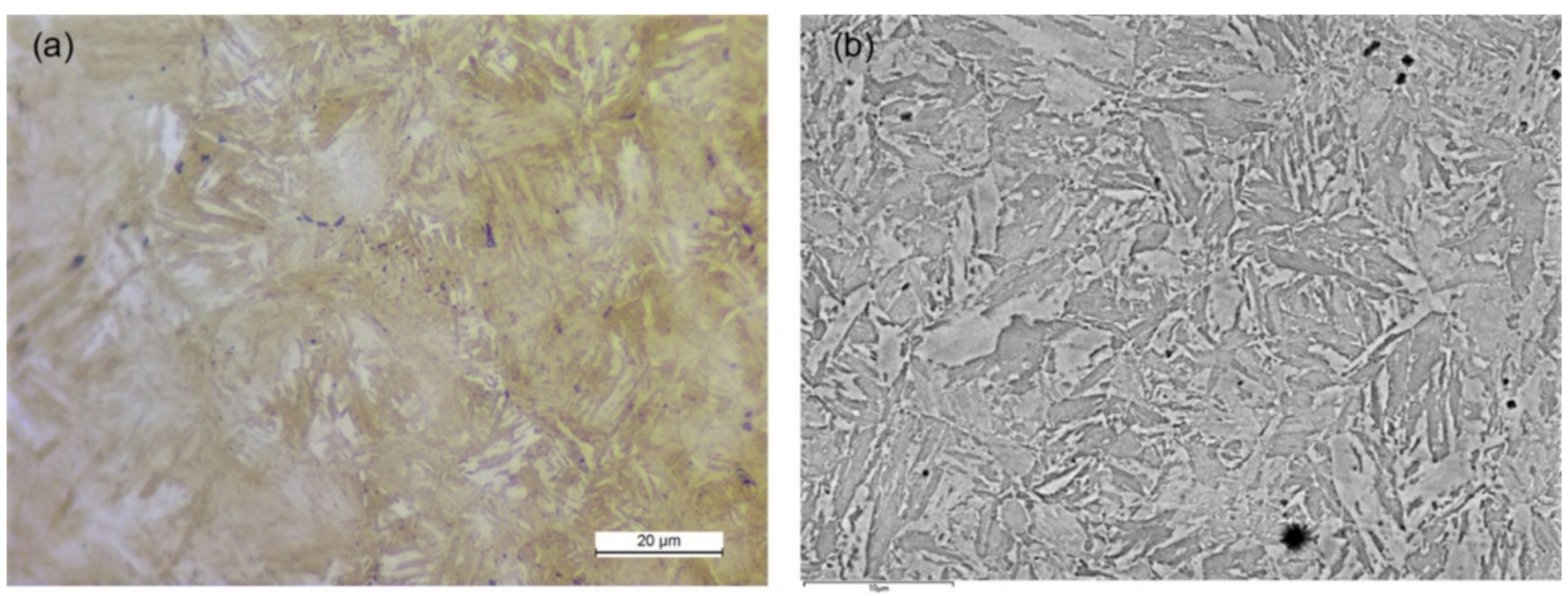

\section{Figure 7}

The hardened zone of the AISI 4340 steel (a) optical micrograph (b) SEM. 


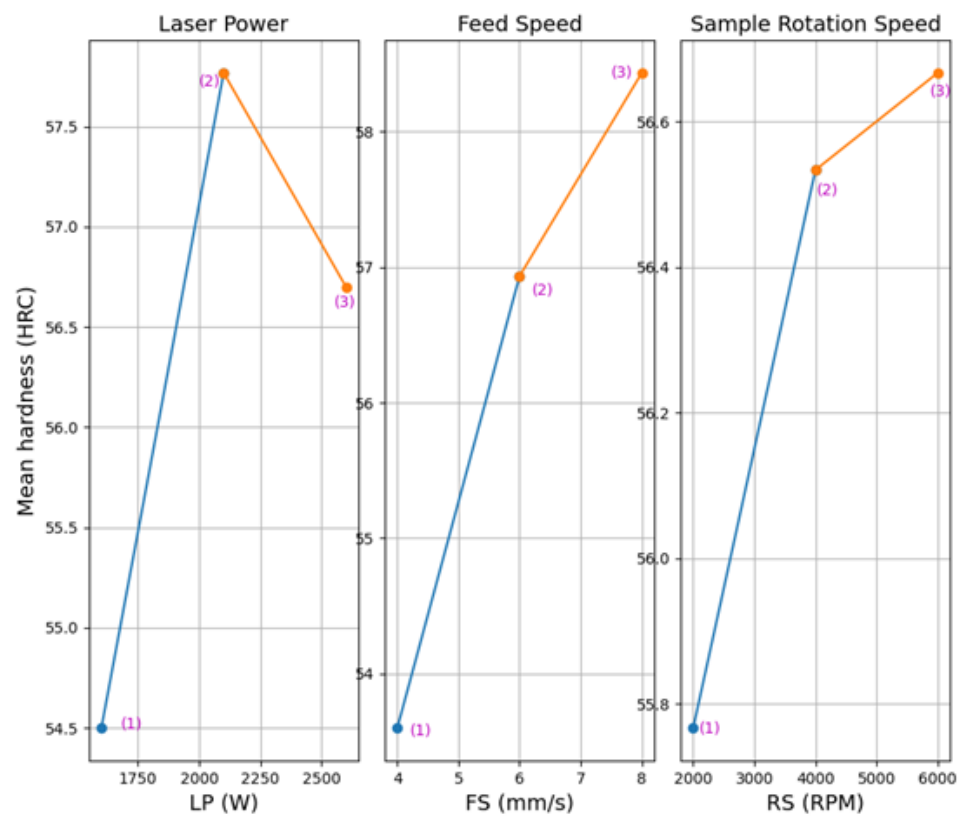

Figure 8

Graph of the main effects for the hardness.
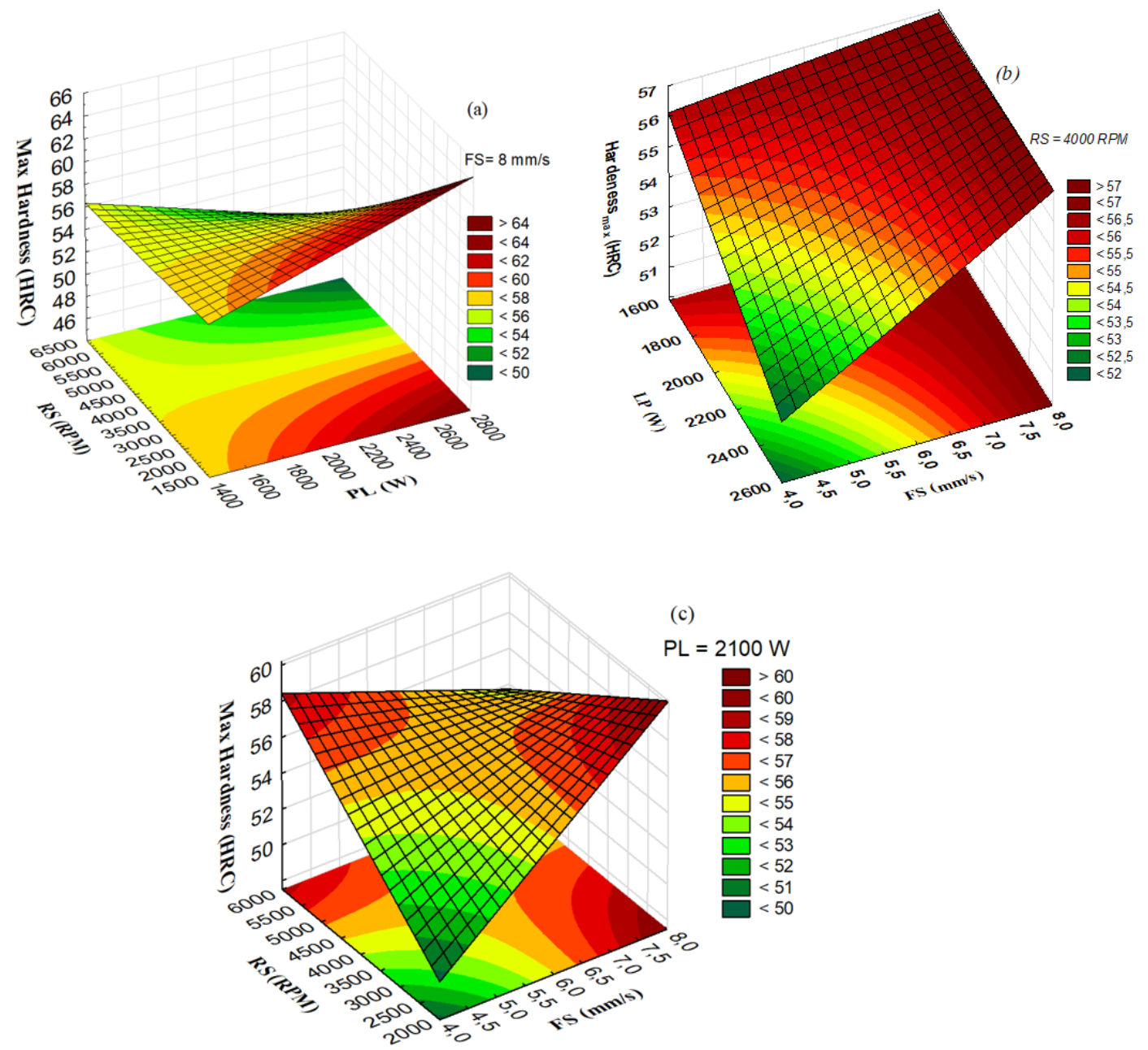
Surface evolution of the maximum hardness as a function of the input parameters LP, FS, and RS.

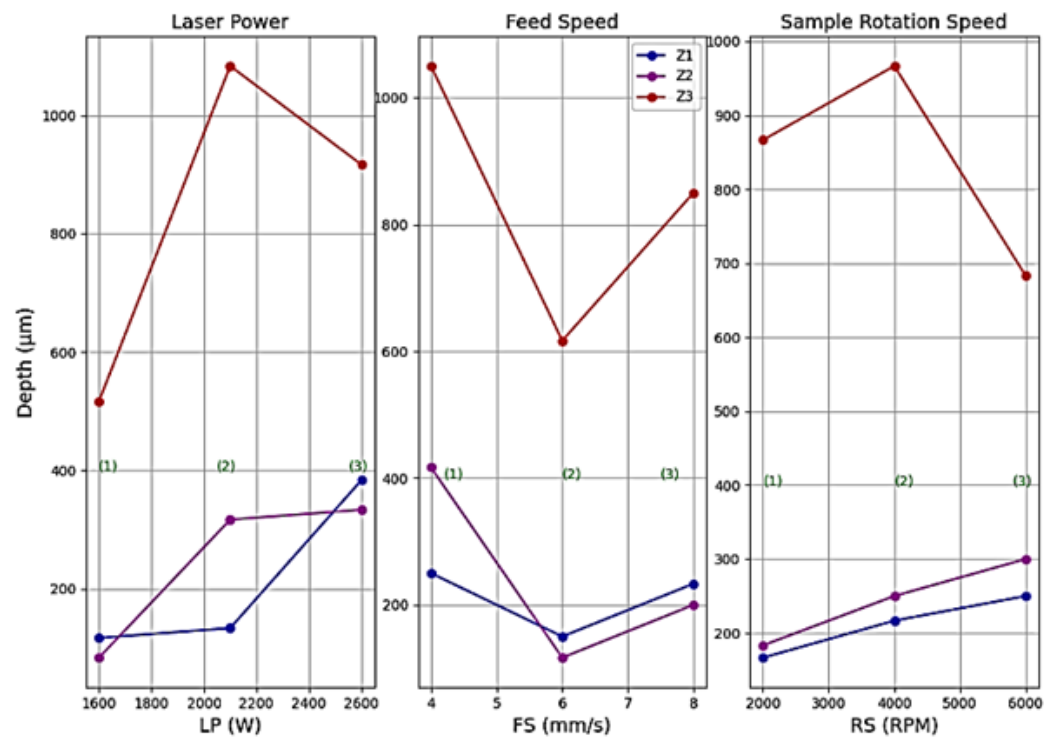

Figure 10

Graph of main effects for hardening depth $Z_{1}, Z_{2}$, and $Z_{3}$.

\section{Figure 11}

Surface evolution of the hardened region depth $Z_{1}$ as a function of the input parameters LP, FS, and RS. 

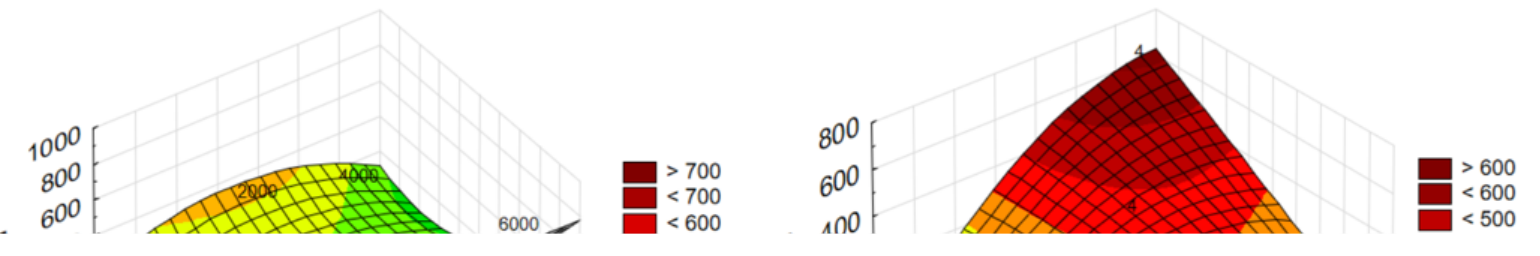

\section{Figure 12}

Surface evolution of the hardness loss region depth $\mathrm{Z}_{2}$ as a function of the input parameters LP, FS, and RS. 


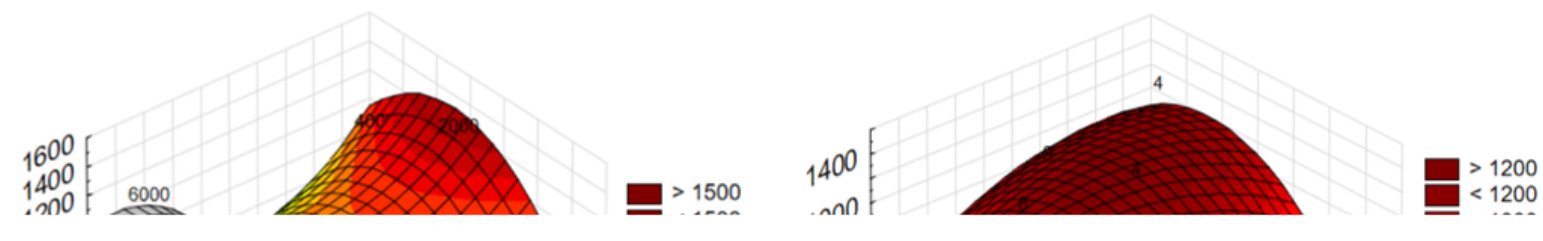

\section{Figure 13}

Surface evolution of the over-tempering region depth $Z_{3}$ as a function of the input parameters LP, FS, and RS.

\section{Supplementary Files}

This is a list of supplementary files associated with this preprint. Click to download.

- Highlights.docx 